\title{
COMPUTATIONAL ALGORITHMS SUPPORTING THE BRIDGE MANAGEMENT SYSTEM
}

\author{
LUCJAN JANAS ${ }^{1 *}$, BARTOSZ MILLER ${ }^{2}$, \\ ADAM KASZYŃSKI ${ }^{3}$ \\ ${ }^{1}$ Dept of Roads and Bridges, Rzeszow University of Technology, Rzeszow, Poland \\ ${ }^{2}$ Dept of Structural Mechanics, Rzeszow University of Technology, \\ Rzeszow, Poland \\ ${ }^{3}$ General Directorate for National Roads and Motorways, Warszawa, Poland
}

Received 10 July 2017; accepted 04 September 2018

\begin{abstract}
This paper presents a novel approach to the creation of a ranking list of bridges with the highest priority for repair, renovation or exchange. Two main aspects addressed herein are studied. First concerning parameters, which must be taken into account while creating the list of bridges with priority for repair or renovation. Second concerning proposition of algorithms for creating such list. A set of factors that affect this priority has been created; the three main ones were selected: technical condition factor, safety factor and the importance for the roads network factor. Three self-reliant algorithms of the ranking list creation are presented. One of them is the so-called "expert algorithm", based on artificial neural networks - gives the best result and has been indicated as the recommended one. This algorithm, engaging back-propagation multilayer artificial neural network, is implemented in the General Directorate for National Roads and Motorways in Poland and is applied as a supporting tool in managing road-engineering structures.
\end{abstract}

Keywords: algorithm, bridges, neural networks, ranking list, renovation, technical condition.

\footnotetext{
* Corresponding author. E-mail: ljanas@prz.edu.pl 


\section{Introduction}

Polish national roads and motorways network currently includes about seven thousand bridges of different types. The problem of creating an impartial list of bridges that have to be repaired in the first instance is a challenging task. The General Directorate for National Roads and Motorways (abbreviation in Polish GDDKiA) needs a tool for creating such a list using different kinds of data collected in databases, concerning, e.g. technical condition of bridges.

The primary criterion determining the priority for repair was often the technical condition of investigated objects. This approach has not taken into account any other relevant factors, such as safety of pedestrians in case of the lack of sidewalks, too small clearance gauge on or under the bridge or too low (reduced) load carrying capacity. As a result, bridges in good technical condition but risky for pedestrians had a low priority for repair than bridges safe for pedestrians but in a worse technical condition. The assessment of the technical condition is a significant factor in creating a list of objects indicating the need for renovation. It describes the characteristics of objects unsatisfactorily. This problem is widely discussed by Cremona (2014), Liu \& Frangopol (2005), Omer (2005), Parke, Disney, Inagaki, Fujino, Kitagawa, \& Kawamura (2005), and Woodward, Cullington, Daly, Vassie, Haardt, Kashner, ... \& Mahut (2001). Parameters of prioritising the roadway bridges to repair and maintenance are deliberated by Amini, Nikraz, \& Fathizadeh (2016), Bocchini \& Frangopol (2012), Ives \& Jandu (2005), Pai, Gualtero, Alvi, Sen, \& Mullins (2016), Valenzuela, de Solminihac, \& Echaveguren (2009), and Zhang \& Wang (2017). The needs for a systematic methodology for priority ranking of the bridges for

Table 1. Technical condition factor $F_{t}$ and corresponding object elements description (Directive 2005/14/GDDKiA)

\begin{tabular}{cll}
\hline $\boldsymbol{F}_{\boldsymbol{t}}$ & \multicolumn{1}{c}{ Condition } & \multicolumn{1}{c}{ Description } \\
\hline 5 & suitable & no damage or dirt found during the inspection \\
\hline 4 & satisfactory & $\begin{array}{l}\text { the first signs of dirt or damage influencing } \\
\text { the aesthetic appearance }\end{array}$ \\
\hline 3 & worrying & $\begin{array}{l}\text { damage, which left unrepaired shorten the safe } \\
\text { operation period }\end{array}$ \\
\hline 2 & insufficient & $\begin{array}{l}\text { damage possible to be repaired but reducing } \\
\text { the usefulness }\end{array}$ \\
\hline 1 & alarming & irreversible damage disqualifying usefulness \\
\hline 0 & emergency & destroyed or inexistent \\
\hline
\end{tabular}


rehabilitation and allocation of funding described by Augeri, Colombrita, Greco, \& Sapienza (2014) Bolar, Tesfamariam, \& Sadiq (2013), Elbehairy, Elbeltagi, Hegazy, \& Soudki (2006), and Sasmal, Ramanjaneyulu, \& Lakshmanan (2007).

In Poland, the assessment of the technical condition of bridges is done at least once a year by visual inspections carried out according to instructions of inspections of road engineering objects (Directive 2005/14/GDDKiA). Technical condition of all parts of an investigated bridge is evaluated on a scale from 0 to 5 . The mandatory rules of rating the main structural elements of the object are presented in Table 1.

The final value of the technical condition factor is called the overall object assessment, and it is the minimum derived from among the following:

- the mean of the assessment given to all the structural elements investigated during the inspection;

- the assessment is given to the deck;

- the assessment is given to the main girders;

- the assessment is given to the supports.

As it was mentioned above, another important criterion for the renovation necessity is the safety of public movement (herein user safety) and the object safety. User safety is determined mainly by the technical state of the roadway, sidewalks, access roads, balustrades, protective barriers, expansion joints and road sign facilities. User safety also depends on the width and height of the clearance gauge and the applied technical solutions, e.g. type of girders. Object safety relies mainly on the technical condition of spans, deck and supports, load carrying capacity (the lower the capacity, the higher the probability of overload). Moreover, the safety factor is low in the case of objects with beams of types causing frequent crashes.

Apart from the technical state and user/object safety, also other factors have been taken into account while creating a list of objects indicating the need for renovation. These are load capacity, object clearance gauge height and width, clearance gauge below the object, the speed limit for vehicles passing the object. The parameters characterise so-called "usability" and take the values of 0,2 or 5 (Table 2). Some of the parameters are taken into account both as independent factors and as partial parameters influencing the main factors.

Apart from the technical state of object and usability, other parameters are also taken into account: a class of the road, traffic and location of the bridge. Bridges located in industrial and urban areas have higher priority for repair. The traffic problems in such areas have a more significant impact on the economy and living conditions than in the case 
in "usability" assessment (Directive 2005/14/GDDKiA)

\begin{tabular}{cll}
\hline Note & Usability & \multicolumn{1}{c}{ Description } \\
\hline 5 & sufficient & $\begin{array}{l}\text { the parameter fulfils or exceeds the requirements } \\
\text { of users }\end{array}$ \\
\hline 2 & limited & $\begin{array}{l}\text { the parameter does not fulfil the requirements } \\
\text { of users or fulfils partially, no instant repairs are } \\
\text { necessary }\end{array}$ \\
\hline 0 & insufficient & $\begin{array}{l}\text { the parameter does not fulfil the requirements } \\
\text { of users, instant repairs or renovation is necessary }\end{array}$ \\
\hline
\end{tabular}

of undeveloped or rural areas. In addition, the heritage/historical value of the investigated bridge have to be considered, and the approach presented in this paper takes into consideration the historical value of the objects.

All the data required during the algorithm creation phase is available in the GDDKiA databases. The databases contain the data from the last several years and are updating annually.

Some rules of providing the inspection and objective assessment of the technical condition of the investigated object have been developed and gathered in the rules for the application of point grading scale in technical condition assessment and usability of road engineering objects to get consistent results (Directive 2008/64/GDDKiA). Moreover, detailed and specialised courses for inspectors are carried out in carefully selected centres.

\section{Factors considered and their values for the ranking list creation}

The main task of the authors of this paper was to create a numerical algorithm for the determination of the priority of bridges for repair. In other words, the algorithm presented herein must enable the creation of a ranking list where the objects with the highest priority occupy the first positions. A set of factors that affect this priority has been created, the three main ones were:

- technical condition factor: $F_{t}$;

- safety factor: $F_{s}$;

- the importance factor $F_{i}$.

The general way of proceeding is shown in the block diagram in Figure 1. 


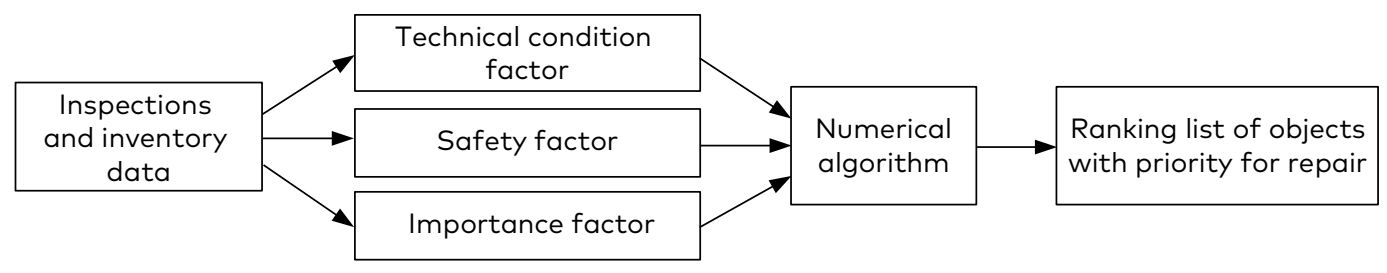

Figure 1. The general scheme for determining the ranking list

\subsection{Technical condition factor}

Technical condition factor $F_{t}$ is equal to "the overall object assessment" given during a recent inspection and placed in an object inspection card by an expert conducting the inspection.

\subsection{Safety factor}

Safety factor $F_{s}$ describes both the user and the safety of the object, the latter being, of course, indirectly connected with the first. The safety factor is calculated as a mean of four partial factors, which are:

a) traffic safety factor, describes any threats/risks to users identified by the inspector during the inspection:

$F_{s 1}=0$, when traffic safety is inadequate, immediate intervention is required,

$F_{s 1}=2$, when safety is limited but immediate intervention is unrequired,

$F_{s 1}=5$, when safety is adequate;

b) technical safety factor describes the probability of failure of objects in the poor technical state

$F_{s 2}=0$ for $F_{t} \leq 1$, where $F_{t}$ is technical condition factor, $F_{t}$ is used here because the technical condition also affects the safety of the structure; when the technical condition is very poor, the structure safety is threatened,

$F_{s 2}=2$ for $1<F_{t}<3$,

$F_{s 2}=5$ for $F_{t} \geq 3$;

c) load capacity factor obtained according to load carrying capacity $N_{u}$ assessed during the in-depth inspection:

$F_{s 3}=0$ for $N_{u}<30 \mathrm{t}$,

$F_{s 3}=2$ for $30 \mathrm{t} \leq N_{u}<42 \mathrm{t}$,

$F_{s 3}=5$ for $N_{u} \geq 42 \mathrm{t}$;

d) structure type factor shows the influence of a structure type on the structure safety: 
$F_{s 4}=0$ for provisional objects, including folding bridges, objects with supports strengthened through provisional mountings, objects with girder types, which often fail, e.g. beams named B6 (Directive 2008/64/GDDKiA),

$F_{s 4}=2$ for structures with girder types, which sometimes fail, e.g. precast concrete unit named Gromnik, CZDP (Directive 2008/64/ GDDKiA),

$F_{s 4}=5$ for all other cases.

\subsection{Object importance factor}

Object importance factor $F_{i}$ takes into account the importance of the object and its usability. The object importance depends, among others, on the class of the road where the object is located, traffic, location, historical significance and the length of a possible detour. The usability depends on load carrying capacity, possible speed limits on the object, the width and height of the loading gauge above/below the object. Object importance factor is calculated as a mean of ten partial factors:

a) road class factor is given as:

$F_{i 1}=0$ for motorways and expressway,

$F_{i 1}=2$ for main roads,

$F_{i 1}=5$ for other roads;

b) traffic load factor takes into account qualitative and quantitative traffic load assessment. Qualitative traffic load assessment is based on a number of trucks passing the object every day and is herein calculated as Average Daily Traffic (ADT, (vpd) (Eq.(1)):

$$
\mathrm{ADT}=\mathrm{AADT}+5 \cdot \mathrm{ADTT} \text {, }
$$

where AADT - average annual daily traffic, vpd; ADTT - average daily trucks traffic (with or without trailers), vpd.

Component 5·ADTT takes into account the high significance of objects passed daily by many trucks; social costs of such objects decommissioning are higher than the costs of decommissioning objects passed daily by passenger cars only. The traffic load factor is defined as follows:

$F_{i 2}=0$ for $\mathrm{ADT}>25000 \mathrm{vpd}$,

$F_{i 2}=2$ for $10000 \mathrm{vpd}<\mathrm{ADT} \leq 25000 \mathrm{vpd}$,

$F_{i 2}=5$ for $\mathrm{ADT} \leq 10000 \mathrm{vpd}$;

c) location factor represents the fact that objects located in industrial or metropolitan areas are more critical for road networks (from the economical point of view) than objects in medium-sized towns or rural areas; due to the availability of data in the GDDKiA database the following values are used:

$F_{i 3}=2$ location in the industrial or metropolitan area, $F_{i 3}=5$ location in rural areas; 
d) historical value factor:

$F_{i 4}=0$ for historical objects,

$F_{i 4}=5$ for other objects;

e) detour length factor:

$F_{i 5}=0$ when either detour length is over $50 \mathrm{~km}$ or provisional bridge is built,

$F_{i 5}=2$ detour length is between $5 \mathrm{~km}$ and $50 \mathrm{~km}$,

$F_{i 5}=5$ detour length is up to $5 \mathrm{~km}$;

f) load carrying capacity factor, the objects with a low load carrying capacity to reduce safety and cause significant impediment to traffic:

$F_{i 6}=0$ for $N_{u} \leq 30 \mathrm{t}$,

$F_{i 6}=2$ for $30 \mathrm{t}<N_{u}<42 \mathrm{t}$,

$F_{i 6}=5$ for $N_{u} \geq 42 \mathrm{t}$;

g) speed limit factor, assumed according to usability:

$F_{i 7}=0$ speed limit on the object is lower by at least $30 \mathrm{~km} / \mathrm{h}$ than on access roads,

$F_{i 7}=2$ speed limit on the object is lower by $10-30 \mathrm{~km} / \mathrm{h}$ than on access roads,

$F_{i 7}=5$ speed limit on the object is equal to or higher than on access roads;

h) clearance gauge width factor that is assessed by usability:

$F_{i 8}=0$ gauge width is insufficient,

$F_{i 8}=2$ gauge width is limited,

$F_{i 8}=5$ gauge width is sufficient;

i) clearance gauge height factor that is assessed by usability:

$F_{i 9}=0$ gauge height is insufficient,

$F_{i 9}=2$ gauge height is limited,

$F_{i 9}=5$ gauge height is sufficient;

j) clearance gauge below the object factor assessed by the usability:

$F_{i 10}=0$ gauge height is insufficient,

$F_{i 10}=2$ gauge height is limited,

$F_{i 10}=5$ gauge height is sufficient.

\section{The creation algorithm of a list of objects with priority for repair}

\subsection{General comments}

The first task during the algorithm creation process was the compilation of benchmark examples. A team of seven experienced GDDKiA experts, and a set of 103 objects (significantly varying in their
Computational

Algorithms

Supporting

the Bridge

Management

System 
technical condition, safety and the importance of the road network) were selected. The experts obtained detailed data concerning all the investigated objects, including photographic documentation and all other information available in the GDDKiA databases. After a careful review and discussion, the experts created an overall ranking list prioritising the objects requiring renovation in the first instance; this list is called herein the "expert list". The main research task described in this paper was designing an algorithm for automatic creation of such ranking list. Three approaches were tested and verified through the comparison to the list of experts. The tested algorithms were technical condition priority algorithm, safety priority algorithm, Artificial Neural Network (ANN) algorithm (herein expert algorithm).

\subsection{Technical condition priority algorithm}

Technical condition priority algorithm takes into account mainly the technical condition of the objects. The ranking list of objects with priority for repair is obtained by sorting the list of objects according to three keys. The main one is the technical condition factor $F t$, the second one is safety factor $F_{s}$ and, as the least significant, the factor of object importance to road network $F_{i}$. At the beginning of the list, some objects have the lowest technical condition factor. When several objects have the same technical condition, high on the list are those with a low safety factor.

Figure 2 shows the comparison of the expert list with the list of objects for repair obtained from technical condition priority algorithm, for the first 30 objects.

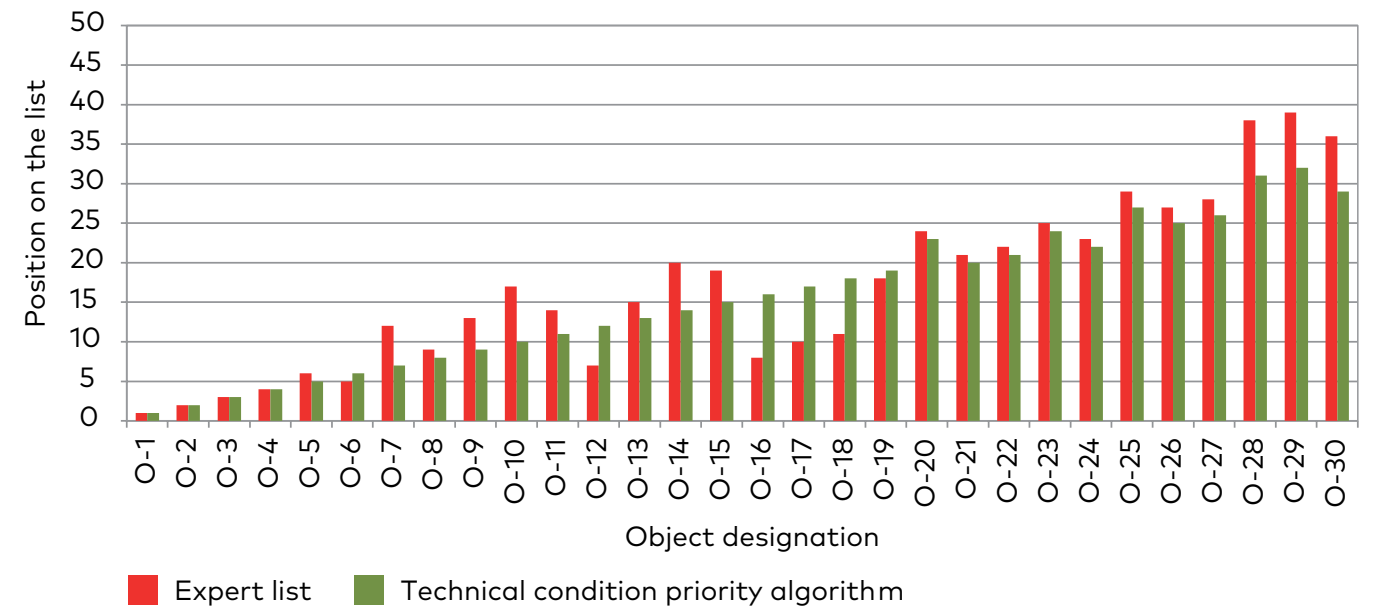

Figure 2. Comparison of a position in the expert list and the list created by the technical condition priority algorithm 
The resultant ranking list significantly differs from the expert Computational Algorithms list. According to this list object named $0-28$ is in the $38^{\text {th }}$ position, while the technical condition priority algorithm placed it in position number 32. The average error of object location on the resultant ranking list (in comparison to the expert list) equalled 4.3. The maximal error reached 28.

\subsection{Safety priority algorithm}

Since the results obtained from the technical condition priority algorithm were unsatisfactory, the safety priority algorithm was checked. The ranking list was again arranged by sorting the list of objects according to three keys. This time the sorting keys were as follow: the main one was safety factor $F_{s}$, the second one was technical condition factor $F_{t}$ and as the least significant, the factor of importance of objects to road network $F_{i}$. At the beginning of the list, some objects have the lowest safety factor. When several objects have the same safety factor, high on the list are those with a low technical condition factor.

Figure 3 shows the comparison of the expert list with the list of objects for repair obtained from safety priority algorithm, for the first 30 objects.

The resultant ranking list significantly differs from the expert list. According to this list object named $0-28$ is in the $38^{\text {th }}$ position, while the safety priority algorithm placed it in position number 48 . The average error of object location on the resultant ranking list (in comparison to the expert list) equalled 2.5. The maximum error reached 16.

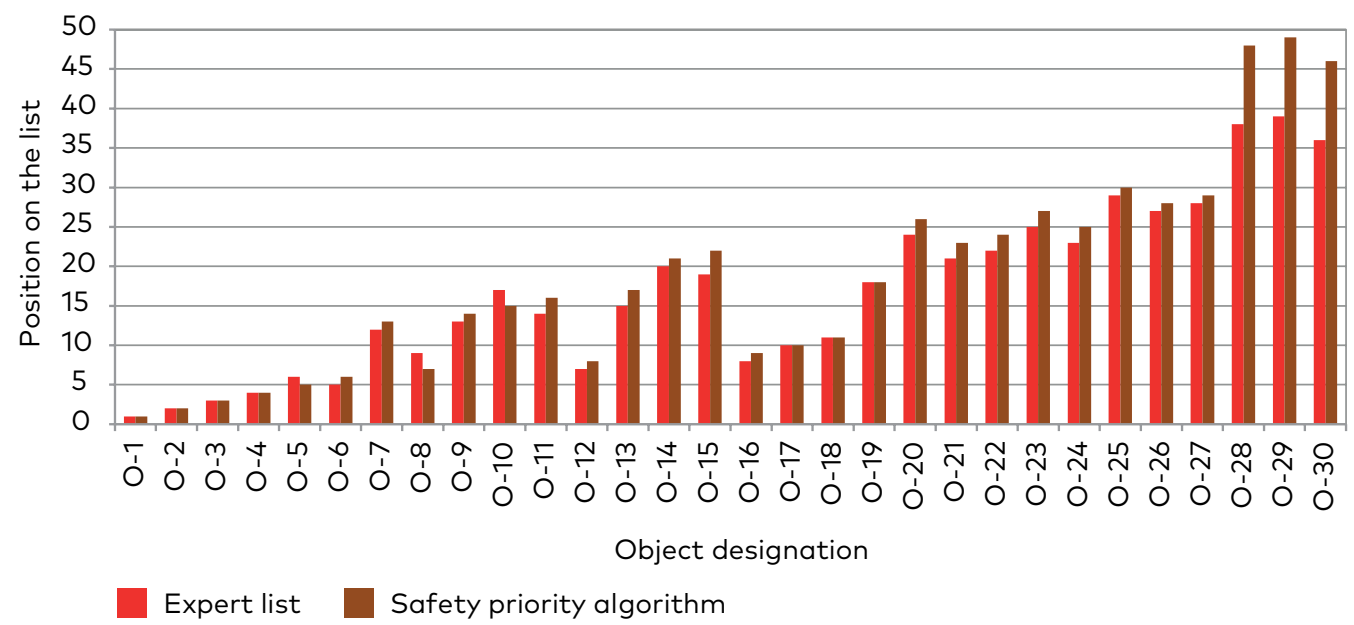

Figure 3. Comparison of a position in the expert list and the list created by the safety priority algorithm 
The results were again unsatisfactory. Therefore, an entirely new algorithm has been proposed, the so-called expert algorithm, involving a modern soft-computing tool called Artificial Neural Networks (ANN).

\subsection{Expert algorithm}

Artificial neural networks (Fedele, Maier, \& Miller, 2006; Miller, 2010; Ziemianski, Miller, \& Piatkowski, 2007) were initially created as minimum limited models of a human brain. They are no more treated as mathematical models of biological neural networks; nevertheless, some common features are still visible. The multi-layer perceptron, classical ANN applied herein, is built of some units called artificial neurons. The neurons are usually grouped in layers and are connected to each neuron in adjacent layers but not to the neurons in the same layer. The first layer of this kind of ANN obtains and linearly scales the input data vector (the number of input vector elements and the number of input neurons must be equal). Then passes the transformed vector to the next, hidden layer. In the hidden layer, the main processing takes place, namely:

- each neuron in the hidden layer sums the outputs of all the input neurons (earlier the output values are multiplied by scalars called synaptic weights, unique for a particular neuron-to-neuron connection) together with an additional input called bias;

- the resulting sum is an argument of a nonlinear function (so-called neuron activation function), the result of which is given to the neuron output.

Output values of neurons in the hidden layer are passed through synaptic connections (and multiplied by synaptic weights) to the output layer, where processing similar to the one in a hidden layer takes place (usually a linear activation function is used in output layer neurons). The outputs of neurons in an output layer are treated as the outputs of the whole ANN.

If one considers an example of one-hidden-layer ANN transforming a 3-element input vector into one scalar, the architecture of this ANN is given as $3-h-1$, where 3 is the number of input neurons (neurons in an input layer), $h$ is the number of neurons in a hidden layer, and 1 is the number of neurons in an output layer (equal to one in case of onedimensional output space). The number of synaptic connections between three neurons in an input layer and $h$ neurons in a hidden layer is equal to $3 h$, the number of connections between $h$ neurons in the hidden layer and a single neuron in the output layer is equal to $h$, the overall number of connection is, therefore, equal to $3 h+1 h$. Each of those connections has its unique synaptic weight value. Moreover, each neuron from the hidden and output layers has its additional input called bias. Both synaptic weights and biases are parameters to be obtained during 
network tuning process, the total number of those network parameters is, in case of a 3-h-1 network, equal to $(3 h+1 h)+(h+1)=5 h+1$.

The iterative procedure for determining the values of synaptic weights and biases is called learning (or training). Initial values of the parameters are randomly generated, in the majority of cases from among the range of $(-1,1)$. In each iteration step (called epoch) some examples (consisting of known, prepared in advance input vector and corresponding output vector) are presented to the network. The network calculates output values for a given input vector and compares the result with the expected output vector. According to the difference between the expected and the obtained output vectors, the values of network parameters - synaptic weights and biases - are corrected. The algorithm describing the process of correcting network parameters is called error backpropagation.

Each example, containing an input vector and a corresponding output vector, and presented to the network during learning, is called pattern. The learning algorithm converges to a global minimum of the error function (obtained as a difference between the expected and the obtained outputs) when a set of patterns is properly prepared. It means the number of patterns is higher than the number of three network parameters, and the patterns cover the whole considered input space.

As soon as the learning process is finished, e.g. when the network error converges to a constant value, or the number of epochs reaches previously set limit value, the accuracy of a learned network is verified using new patterns, not presented to the network during the learning procedure. It allows the assessment of the so-called generalisation abilities of a network showing its potential to work with unknown data. In this paper the ANN, called the multi-layer perceptron, with error backpropagation learning algorithm has been applied.

The assumption has been made that ANNs use the same input data as the two previously described algorithms, technical state priority and safety priority algorithms. The task of the ANN is to assign to each considered objects the priority of repair expressed in points (the lower the number of assigned points the higher the priority for repair), in other words, to transform three-element input vector $x$ into one scalar $y$. The input vector is defined as Eq. (2):

$$
x=\left\{F_{t} ; F_{s} ; F_{i}\right\} \text {, }
$$

where $F_{t}$ is a technical condition factor, $F_{s}$ is a safety factor, $F_{i}$ is an object importance factor (as it was described in subsections 1.1-1.3).

The output vector consists of one value only, namely the priority for repair: $y=\{p\}$. The idea of ANN application is presented as an Eq (3):

$$
\left\{F_{t} ; F_{s} ; F_{i}\right\} \rightarrow \frac{\mathrm{ANN}}{3-3-1} \rightarrow\{p\} .
$$

Computational

Algorithms

Supporting

the Bridge

Management

System 
To determine the optimal value of $h$ (the number of neurons in a hidden layer) and to tune the neural network parameters (synaptic weights and biases) a set of patterns is necessary. The patterns must contain reliable information covering the full range of input variables that occur in real cases, include the input data and the corresponding output values. Herein 103 objects were precisely described, and their parameters were used to create 103 input vectors, the corresponding output values were taken like locations on the expert list of priority for repair (subsection 2.1.). During learning of the network, 62 of the patterns were used as learning ones, 21 were used to determine optimal neural network architecture, and the remaining 21 were used to check the generalisation abilities of the obtained ANN. Final tests were performed on adding new objects that were described and appropriate patterns created when the learning process was finished.

The determination of optimal $h$ value consisted of one hundred repetitions of the learning process for each value of $h$ in the range from 1 to 15 , each time starting from different, randomly generated starting values of network synaptic weights and biases. Multiple repetitions of the learning process were performed to check whether each initial, randomly generated a set of network parameters leads to the same

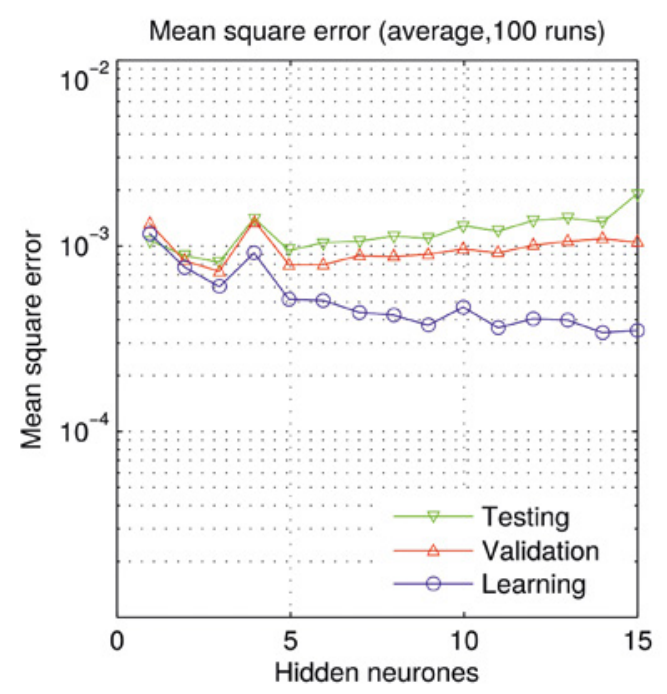

a) position determined by a trained neural network for different values of $h$

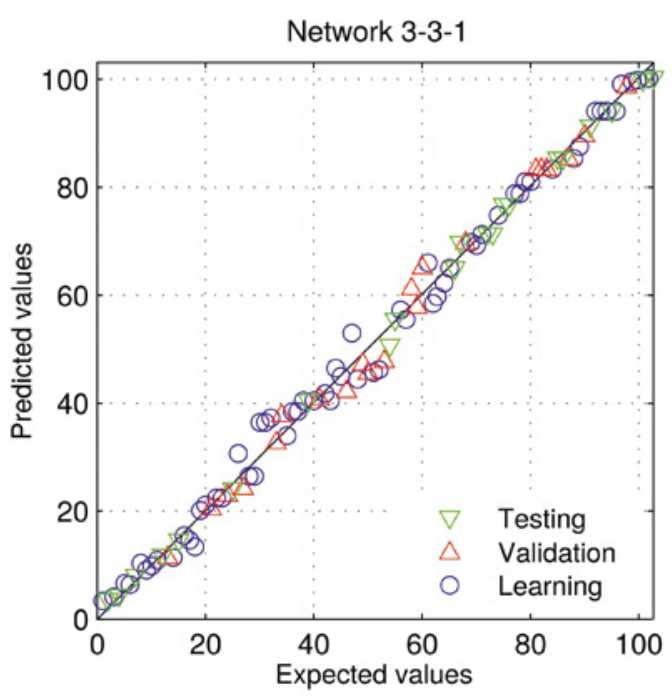

b) results of learning, testing and validation of selected ANN

Figure 4. Mean square error among reference positions in the ranking list 
minimum. If the results of subsequent repetitions are consistent, it Computational Algorithms means that learning leads to a global minimum.

Figure 4a shows the mean square error between a reference position in the ranking list and the position determined by a trained neural network (error is averaged over 100 runs learning performed for a fixed $h$ ). The upper line in Figure 4a shows the results obtained for testing patterns, the middle one - for validation patterns, the lower one - for learning patterns. With the increasing number of hidden neurons, the accuracy of learning increases as well while the accuracy of testing after an initial increase (the mean square error decreases) begins to grow (the error increases). This a classic phenomenon often observed during learning of ANN, called overfitting. It is caused, e.g. by an insufficient number of learning patterns or too many iterations in the learning process. For further analysis, the optimal number of hidden neurons was chosen as $h=3$.

Figure $4 \mathrm{~b}$ shows the results of the determined priority of objects for repair, on the horizontal axis expected values are shown (set by GDDKiA experts) and on the vertical one, values predicted by a trained ANN. The results obtained for learning patterns are marked with circles, testing and validation results are marked with triangles pointing downwards (testing) or upwards (validation). In the case of the ideal ANN prediction, all the points are placed on the diagonal $x=y$. As it is shown, the ANN prediction accuracy is not ideal but still very good.

Figure 5 shows the comparison of the expert list with the list for repair obtained from neural networks algorithm, herein called the

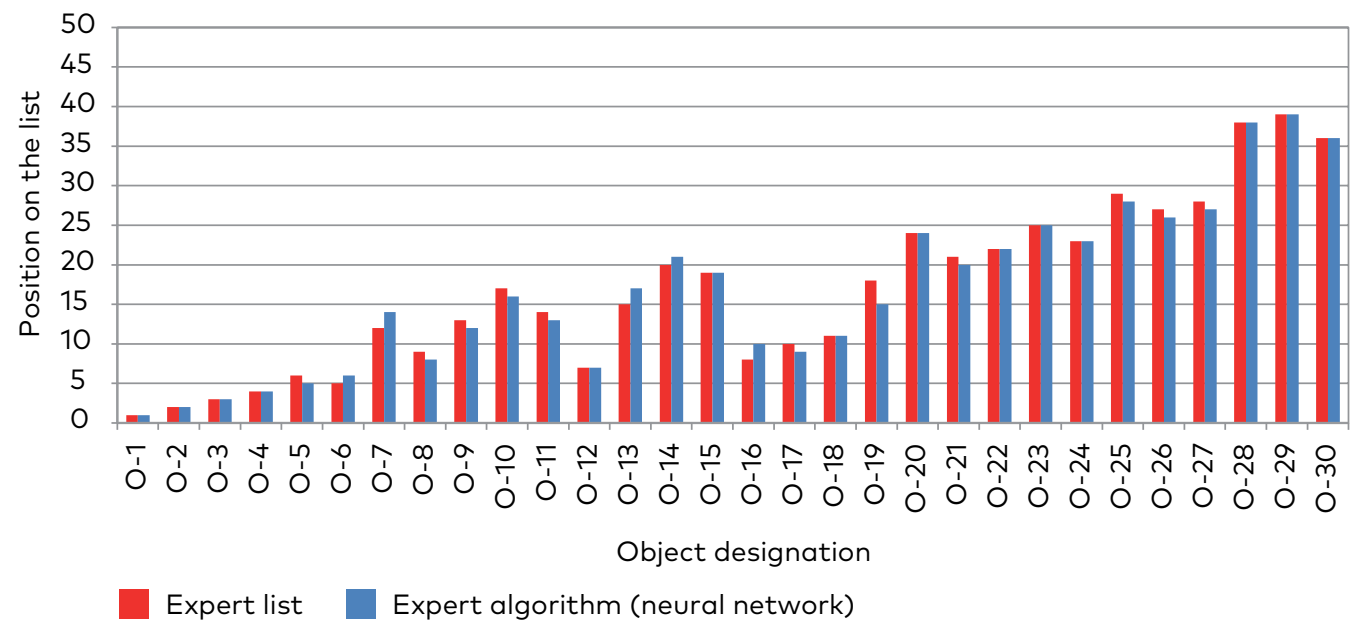

Figure 5. Comparison of a position in the expert list and the list created by the expert algorithm 


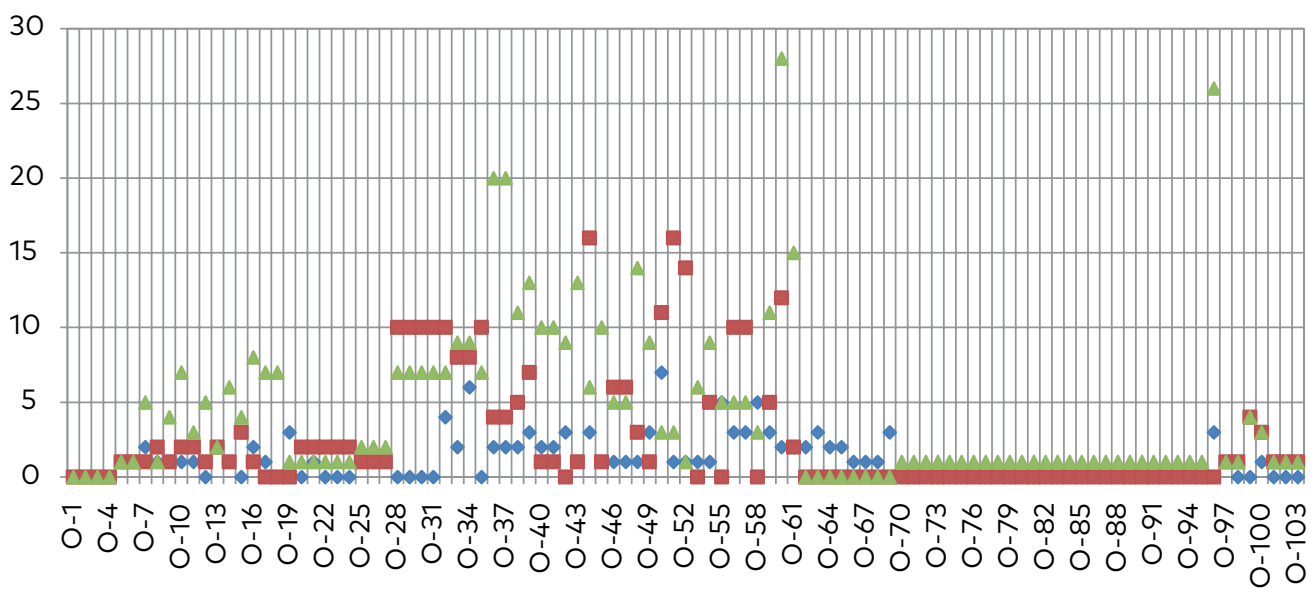

Object designation

Expert algorithm (neural network)

Safety priority algorithm

Technical condition priority algorithm

Figure 6. Comparison of average errors of object location on the resultant ranking list

expert algorithm, for the first 30 objects. The average error of object location on the resultant ranking list (in comparison to the expert list) equalled 1.1. The maximal error reached 7.

Figure 6 shows the results of the three algorithms described in the paper. The expert algorithm involving ANNs is far more accurate than the two others is and produces satisfactory results.

The safety priority algorithm gave the maximum shift of an object position equal to 16 items while the expert algorithm, involving ANNs, gave the maximal shift equal to 7 items. Up to 28 items shifted, the technical condition priority algorithm proved the less accurate one, the position of an object on a ranking list (in comparison to the expert list).

\section{Final remarks and conclusions}

The main objective of bridge management is the achievement of the designed "lifespan" by each bridge at a minimal cost, in a proper condition and the ability for the bridge to be used without distractions and with the minimal risk of failure. To achieve this goal the experts have to analyse the entire set of bridges and to create ranking lists of objects that have to be repaired in the first instance. 
The basis for the creation of such an impartial ranking lists is a reliable computer database describing the bridges, which are under care. General Directorate for National Roads and Motorways in Poland has such a database.

This paper presents three self-reliant algorithms of the ranking list creation. One of them, so-called "expert algorithm", based on neural networks, gives the best result and has been indicated as the recommended one. The ranking lists are created without any help of human experts - this is the main benefit of this algorithm.

Nevertheless, all three algorithms have been implemented under the administration of General Directorate for National Roads and Motorways, and in the first years, for comparative purposes, all three are applied. Since all of those are based on data from the same database, it does not increase costs.

The self-reliant algorithm of ranking list creation is only the supporting tool in managing road-engineering structures; it facilitates an impartial choice of objects (from among a set of several thousand) which require repairs in the first instance. In future years, it will be verified and improved.

The application of proposed algorithms does not provide a substitute for an experienced engineer managing the road infrastructure. However, it is expected to assist the engineer in decision-making and thus to contribute to the improvement of safety and more efficient use of budget funds.

\section{REFERENCES}

Amini, A., Nikraz, N., \& Fathizadeh, A. (2016). Identifying and evaluating the effective parameters in prioritization of urban roadway bridges for maintenance operations. Australian Journal of Civil Engineering, 14(1), 23-34. https://doi.org/10.1080/14488353.2015.1092640

Augeri, M. G., Colombrita, R., Greco, S., \& Sapienza, P. (2014). Dominance-based rough set approach to network bridge management, The Baltic Journal of Road and Bridge Engineering" 9(1): 31-42. https://doi.org/10.3846/bjrbe.2014.05

Bocchini, P., \& Frangopol, D. M. (2010). Optimal resilience-and cost-based postdisaster intervention prioritization for bridges along a highway segment. Journal of Bridge Engineering, 17(1), 117-129. https://doi.org/10.1061/(ASCE)BE.1943-5592.0000201

Bolar, A., Tesfamariam, S., \& Sadiq, R. (2013). Management of civil infrastructure systems: QFD-based approach. Journal of Infrastructure Systems, 20(1), 04013009. https://doi.org/10.1061/(ASCE)IS.1943-555X.0000150

Cremona, C. (2014). Assessment of existing structures in France: Standard and advanced practices. Bridge Maintenance, Safety, Management and Life Extension, 27.
Computational

Algorithms

Supporting

the Bridge

Management

System 
Directive 2005/14/GDDKiA Instrukcje przeprowadzania przeglądów drogowych obiektów inżynierskich (in Polish)

Directive 2008/64/GDDKiA Zasady stosowania skali ocen punktowych stanu technicznego i przydatności do użytkowania drogowych obiektów inżynierskich (in Polish)

Elbehairy, H., Elbeltagi, E., Hegazy, T., \& Soudki, K. (2006). Comparison of two evolutionary algorithms for optimization of bridge deck repairs. ComputerAided Civil and Infrastructure Engineering, 21(8), 561-572. https://doi.org/10.1111/j.1467-8667.2006.00458.x

Fedele, R., Maier, G., \& Miller, B. (2006). Health assessment of concrete dams by overall inverse analyses and neural networks. International Journal of Fracture, 137(1-4), 151-172. https://doi.org/10.1007/s10704-006-6582-7

Ives, D. A., \& Jandu, A. S. (2005). Maintenance Prioritization of Highway Structures, in In Bridge Management 5: Inspection, Maintenance, Assessment and Repair. Proceedings of The 5th International Conference on Bridge Management, Organized by the University of Surrey, 11-13 April 2005.

Liu, M., \& Frangopol, D. M. (2005). Bridge annual maintenance prioritization under uncertainty by multiobjective combinatorial optimization. Computer-Aided Civil and Infrastructure Engineering, 20(5), 343-353. https://doi.org/10.1111/j.1467-8667.2005.00401.x

Miller, B. (2010, September). Application of semi-Bayesian neural networks in the identification of load causing beam yielding. In International Conference on Artificial Neural Networks (pp. 97-100). Springer, Berlin, Heidelberg. https://doi.org/10.1007/978-3-642-15819-3_13

Omer, S. (2005). Potentials of a Knowledge-Based System for Bridge Management Optimization. In Bridge Management 5: Inspection, Maintenance, Assessment and Repair. Proceedings of The 5th International Conference on Bridge Management, Organized by the University of Surrey, 11-13 April 2005.

Pai, N., Gualtero, I., Alvi, A., Sen, R., \& Mullins, G. (2016). Prioritization Strategy for Replacing Deteriorating Partial-Depth Precast Concrete Deck Panels in Florida. Journal of Bridge Engineering, 21(6), 05016001. https://doi.org/10.1061/(ASCE)BE.1943-5592.0000886

Parke, G., Disney, P., Inagaki, H., Fujino, Y., Kitagawa, K., \& Kawamura, K. (2005). The maintenance and management strategy of bridges for local government in Japan. In Bridge Management 5: Inspection, Maintenance, Assessment and Repair. Proceedings of The 5th International Conference on Bridge Management, Organized by the University of Surrey, 11-13 April 2005.

Sasmal, S., Ramanjaneyulu, K., \& Lakshmanan, N. (2007). Priority ranking towards condition assessment of existing reinforced concrete bridges. Structure and Infrastructure Engineering, 3(1), 75-89. https://doi.org/10.1080/15732470500473549

Valenzuela, S., de Solminihac, H., \& Echaveguren, T. (2009). Proposal of an integrated index for prioritization of bridge maintenance. Journal of Bridge Engineering, 15(3), 337-343. https://doi.org/10.1061/(ASCE)BE.1943-5592.0000068 
Woodward, R., Cullington, D., Daly, A., Vassie, P., Haardt, P., Kashner, R., ... \& Computational Mahut, B. (2001). Bridge Management in Europe (Brime)-Deliverable D14-Final Report.

Zhang, W., \& Wang, N. (2017). Bridge network maintenance prioritization Algorithms

Supporting the Bridge Management under budget constraint. Structural safety, 67, 96-104. https://doi.org/10.1016/j.strusafe.2017.05.001

Ziemianski, L., Miller, B., \& Piatkowski, G. (2007). Application of Neurocomputing to Parametric Identification Using Dynamic Responses. In Intelligent Computational Paradigms in Earthquake Engineering (pp. 362-392). IGI Global. 